\title{
Perceptions of High School Counseling Activities: Response Differences According To College Plans
}

By Margaret Libsch and Peter Freedman-Doan

Responses to a survey indicate that seniors' perceptions of their counseling needs often do not coincide with the amount of specific counseling they actually received.

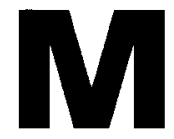

ost secondary schools offer a continuum of student counseling services that include individual counseling sessions, group counseling, and academic advising through college and financial aid planning, and career or vocational guidance.

In recent years administrators, parents, and students have increased their demands for accountability in high school guidance services. In response to these demands counselors have recognized the need to develop some mechanism to monitor student feedback on the effectiveness of guidance programming (West et al., 1991). The results of a national study may provide counselors with a source of student feedback on the delivery of counseling services.

Margaret Libsch and Peter Freedman-Doan are research associates, Monitoring the Future, Survey Research Center, The University of Michigan, Ann Arbor. 
Annually, researchers at the University of Michigan survey a nationwide sample of high school seniors. Among other topics in the survey, seniors are asked a series of questions about their interactions with guidance counselors.

According to overall survey responses, it appears that high school seniors' perceptions of their counseling needs often do not coincide with the amount and types of counseling intervention they actually receive.

The data reported below are drawn from the study, Monitoring the Future: A Continuing Study of American Youth, that has been ongoing since 1975. Each spring about 17,000 seniors participate in a 45 -minute self-administered, in-school, paperand-pencil survey supervised by trained field staff members from the University of Michigan. The sample is nationally representative and includes students from approximately 130 public and private high schools. Study procedures are described in detail elsewhere (Bachman, Johnston, and O'Malley, 1991).

Seniors are asked to respond to a wide variety of questions about personal and social issues, their expectations for the future, and their education and career plans.

A series of questions asks for student perceptions of the quantity and quality of their interactions with guidance counselors during the previous year. We will focus on the items that seek to establish students' preferences for certain types of counseling services, including choosing courses and problems with coursework, discussing trouble gotten into and personal problems, military plans, education or training plans, and career plans or job choice. Table 1 contains the wording of the questions and response categories. For reporting purposes, the five original answer choices for this item were condensed

\section{Table 1 \\ Guidance Items from the Monitoring the Future Survey}

Would you have preferred more or less of each of the following types of counseling in the last year?
a. Choosing what courses to take
b. Discussing problems with course- work
c. Discussing any trouble you've got- ten into
d. Discussing military plans
e. Discussing education or training plans
f. Discussing career plans or job choice
g. Discussing personal problems.

\section{Responses categories:}

$5=$ Much more

$4=$ A little more

$3=$ About right

$2=$ A little less

$1=$ Much less 
into three categories: prefer more, about right, or prefer less.

\section{Seniors' Specific Counseling Preferences}

Seniors' responses to these guidance items have remained fairly stable between 1979 and 1992, the years for which data are available. Because of the stability of the data reported here, Table 2 presents responses only for 1992.

The broad counseling topics included in this series represent several common situations leading students to consult their counselors. We begin by examining two items that may have an impact on students' academic success: choosing courses and problems with coursework.

About half the seniors say they would prefer additional counselor dis- cussion on choosing courses, while slightly fewer say they receive about the right amount. Few students prefer less counselor intervention in the course selection process.

Seniors' academic success also depends to some extent on how they deal with coursework problems. Therefore, it is worth noting that more than one-third of the seniors say they would prefer additional counselor discussion about coursework problems. Approximately half the seniors surveyed say they receive about the right amount of counseling discussion for problems with coursework, while few students prefer less discussion on the topic.

Personal and social development issues may also affect students' high school success. As shown in Table 2, more than half the seniors report

\section{Table 2}

Seniors' Perceptions of Specific Counseling Activities

1992 Percentage Distribution of Responses

\begin{tabular}{lccc}
\hline \multicolumn{1}{c}{ Item } & Prefer More & About Right & Prefer Less \\
\hline Choosing courses & 49 & 43 & 8 \\
Problems with coursework & 37 & 49 & 14 \\
\hline Trouble gotten into & 21 & 56 & 23 \\
Personal problems & 22 & 51 & 28 \\
\hline Discussing military plans & 11 & 45 & 44 \\
\hline Education or training plans & $\mathbf{5 4}$ & $\mathbf{3 4}$ & 12 \\
Career plans or job choice & $\mathbf{6 1}$ & $\mathbf{3 1}$ & 8
\end{tabular}


that they receive the right amount of counseling discussion regarding trouble gotten into. Although about one in five students prefers more counselor discussion on this topic, a slightly larger percentage of seniors prefers less counselor discussion about trouble.

\section{Seniors' academic suc- cess also depends to some extent on how they deal with coursework problems.}

Responses to the personal problem item are similar to those for the trouble item, with about one in five seniors saying they prefer more counselor discussion. More than half the seniors agree that they receive about the right amount of counselor discussion on this topic. Surprisingly, more than one-fourth of seniors prefer less counselor contact to discuss personal problems.

The large proportion of seniors, about one in four, who prefer less discussion of personal problems and trouble gotten into is worth noting. There are several possible explanations for this apparent rejection of counseling service.

Some factors that affect the perception of counselor-student contacts are external to the student, such as availability of the counselor or schedule restrictions, while other factors may be classed as internal. In a recent investigation, West and colleagues (1991) reported that three of the top five reasons offered by students for not participating in counseling services were of the internal variety: shyness, lack of trust, and embarrassment.

Seniors may also be confused as to the nature of the counseling contact itself; therefore, counselors may need to educate students regarding the role and benefits of counseling (Hutchinson and Reagan, 1991). Some seniors who prefer less discussion of personal problems or trouble may also wish to use their own problem-solving strategies rather than turning to the counselor.

Slightly less than half the seniors say they receive the right amount of counseling on military plans, while approximately the same number of seniors say they would prefer less military discussion.

It may be of some interest to examine this item in terms of gender. Although few students overall prefer additional discussion of military plans, more males ( 16 percent) do so than females (6 percent.) Consistent with that, a higher percentage of females (49 percent) than males ( 40 percent) would prefer less military counseling. Similar proportions-44 percent of males and 46 percent of females - say 
they receive the right amount of counseling. We may speculate that the large group of seniors who prefer less discussion of military options feel they are over-exposed to this topic by counselors or have no interest in the military as a career path.

More than half the seniors would prefer additional counseling discussion of education or training plans, while about one-third say they receive the right amount. Only about 1 in 10 students prefers less counselor discussion of education or training plans. This number may include students who enter their senior year with early college acceptances or firm training plans and so have no need for additional planning.

Planning for further education or training, always a topic of great concern for high school students and their parents, has traditionally been recognized as one of the counselor's main functions. Counselors may find it useful to note that responses of the majority of seniors continue to emphasize this importance.

For the career plans or job choice item, a pattern comparable to that described above emerges from the students' responses. This item contains the lowest percentage of seniors who say they receive the right amount of counseling and the highest percentage of those who would prefer more.

Almost two-thirds of seniors would prefer more counselor discussion of career plans or job choice, while very few prefer less. Considering the number of career choices and job options that have vanished from the labor market, and the array of high-tech occupations with which they have been replaced, it seems essential that counselors offer seniors as much and as varied access to career and vocational information as possible.

\section{Response Differences According to College Plans}

The Monitoring the Future study also asks students about their plans to graduate from a four-year college. It is possible, therefore, to compare the counseling preferences of seniors with four-year college plans to the preferences of students without such plans.

\section{Almost two-thirds of seniors would prefer more counselor discussion of career plans or job choice, while very few prefer less.}

Table 3 shows students' 1992 responses to four items categorized into college-bound and non-collegebound groups. The focal itemschoosing courses, military plans, education or training plans, and career plans or job choice-have been selected because students' response patterns reveal intergroup differences that may be of interest to counselors. 
Non-college-bound youth are generally less likely to say that they receive the right amount of counselor intervention on the four focal items. As Table 3 illustrates, the distribution of their responses ranges from 2 to 18 percentage points lower than those of their college-bound peers. Considerably larger proportions of non-college-bound seniors also express a preference for less counseling about each topic. However, a large proportion of seniors in both groupsbetween 47 percent and 63 percent-would prefer more counselor assistance with all items except discussion of military plans.

A clear difference in response patterns emerges between these two groups of seniors for discussion of military plans. The majority of non-college-bound seniors, 53 percent, say they would prefer less counselor discussion, while about two-fifths of the college-bound, 42 percent, would also prefer less discussion of military plans. Although nearly half the collegebound seniors say they receive about the right amount of counseling, less than a third of the non-collegebound seniors agree.

Few seniors say they prefer additional counselor discussion of military plans, although proportionally more of those in the non-college-bound group do so. Feedback generated by this item-that relatively few students in either group prefer more

\section{Table 3}

\section{Seniors' Counseling Preferences: College-Bound, Non-College- Bound}

1992 Percentage Distribution of Responses

\begin{tabular}{llccc}
\hline \multicolumn{1}{c}{ Item } & \multicolumn{1}{c}{$\begin{array}{c}\text { College } \\
\text { Plans }\end{array}$} & $\begin{array}{c}\text { Prefer } \\
\text { More }\end{array}$ & $\begin{array}{c}\text { About } \\
\text { Right }\end{array}$ & $\begin{array}{c}\text { Prefer } \\
\text { Less }\end{array}$ \\
\hline Discussing military plans & College-bound & 9 & 50 & 42 \\
& Non-college & 16 & 32 & 53 \\
\hline Choosing courses & College-bound & 48 & 46 & 6 \\
& Non-college & 50 & 37 & 14 \\
\hline Education or training plans & College-bound & 57 & 35 & 8 \\
& Non-college & 47 & 31 & 22 \\
\hline Career plans or job choice & College-bound & 63 & 32 & 5 \\
& Non-college & 55 & 30 & 15
\end{tabular}


counselor discussion about military plans, that the majority of non-college-bound seniors prefer less, and that more college-bound seniors say they receive about the right amount-may be useful to counselors when presenting military options to high school seniors.

A larger proportion of collegebound seniors agree that they receive the right amount of counseling help on course selection. Although the numbers are small, twice as many non-college-bound students would prefer less of such help.

Some non-college-bound seniors may perceive the counselor's main function to be college-oriented advising, and may reject course selection counseling that is perceived to be less relevant to their needs. When planning counseling activities such as academic advising, it is helpful for counselors to recognize the differences that have emerged between non-college-bound and collegebound students.

Approximately one-third of the seniors in both groups say the amount of counseling they receive for education or training plans is about right. The non-college-bound seniors are more likely to indicate that they prefer less assistance than their college-bound peers.

Counselors may wish to recall that the majority of seniors, with or without four-year college plans, say they desire more counseling with educa- tion or training plans. For the relatively small number of seniors who prefer less counselor intervention we may speculate that some of the noncollege-bound students find the discussion of education or training plans to be less relevant.

\section{Non-college-bound youth are generally less likely to say that they receive the right amount of counselor intervention on the four focal items.}

The few college-bound students who desire less discussion of education or training plans may be reacting to other factors that can affect the planning process, such as parental expectations, peer influences, or the perceived relevance of counseling information (Chapman, DeMasi, and O'Brien, 1991).

The majority of students in each group, nearly two-thirds of the college-bound and more than half of the non-college-bound, would prefer more counselor discussion of career plans or job choice. Less than onethird of the students in both groups say they receive about the right amount of counselor discussion. Although the number is small, a greater number of non-college-bound seniors prefer less counselor discus- 
sion of career plans or job choice than their peers.

Earlier, we touched upon possible reasons why some students may reject counseling services. Student responses reported in Table 3 indicate the value placed upon counselor intervention in the areas of career planning or job choice by most seniors in both the college-bound and non-college-bound populations.

\section{Conclusions}

Seniors' responses to selected guidance items demonstrate their preferences for specific types of counseling activities. In terms of the amount of counselor contact received, both college bound and non-college-bound seniors report that they would prefer more counseling assistance on most topics, especially in career planning or job choice, education or training plans, and assistance with course selection.

High school seniors with four-year college plans report perceptions of guidance counseling services that differ from those of seniors without fouryear college plans. College-bound seniors are more likely than non-college-bound seniors to report that the amount of counseling services they received for specific counseling topics is about right.

A larger proportion of non-college-bound seniors expressed a preference for less counselor intervention in most areas. In search of a possible explanation for the differences between the college-bound and noncollege-bound groups, we examined the issue of student satisfaction using a separate survey item that asks students to rate their satisfaction with counseling contact received.

A review of seniors' responses to that item revealed no basic differences between the two groups. About half the seniors in both groups were satisfied with their counseling contacts, less than one-fifth did not find counseling to be helpful, and about a third of both groups found it to be very helpful.

It appears that satisfaction levels cannot account for the observed differences between college-bound and non-college-bound students. Therefore, the less positive perceptions of the amount of counseling reported by non-college-bound seniors may be due to a disparity between the amount of counseling services they desired and the amount of counseling they actually received.

In assessing the results of this study it is important to note that the survey questions are administered during the final part of the senior year, a period when critical decisions regarding the student's future plans are often made and counseling intervention may be timely. Some students, however, enter their senior year with college or other postsecondary plans already formulat- 
ed and may be less receptive to additional counseling intervention.

It is also important to recall that a number of other factors may affect seniors' perceptions of guidance counseling services, including the unique profile of each school, the characteristics of its student population, and the types of counseling available. It is hoped that the data from the Monitoring the Future study reported here may be used by counselors to generate support within their schools for improvements in the provision of counseling services. $\sim \boldsymbol{B}$

\footnotetext{
*The ongoing Monitoring the Future Project is supported by the National Institutes of Health. Address correspondence to Margaret Libsch, Survey Research Center, Institute for Social Research, University of Michigan, Ann Arbor, Mich. 48106-1248.
}

\section{References}

Bachman, J. G.; Johnston, L. D.; and O'Malley, P. M. "The Monitoring the Future Project After Seventeen Years: Design and Proce. dures." Monitoring the Future Occasional Paper 33. Ann Arbor, Mich.: Institute for Social Research, 1991.

Chapman, D. W.; DeMasi, M.; and O'Brien, C. . "Parents' Perceptions of the Effectiveness of Public School Counselors in College Advising." The School Counselor 38(1991): 268-78.

Hutchinson, R. L., and Reagan, C. A. "Problems for Which Seniors Would Seek Help from School Counselors." The School Counselor 36(1989): 271-79.

West, J. S.; Kayser, L.; Overton, P.; and Saltmarsh, R. "Student Perceptions That Inhibit the Initiation of Counseling." The School Counselor 39(1991): 77-83.

\section{On Education}

I have learned much from my teachers, and from my colleagues more than from my teachers, and from my students more than from all. 